\title{
Direito à participação nas políticas urbanísticas: avanços após 15 anos de estatuto da cidade'
}

Right to participate in the urban policies: progress after 15 years of City Statute

Celso Maran de Oliveira[a], Dulce Lopes ${ }^{[b]}$, Isabel Cristina Nunes de Sousa ${ }^{[0]}$

[a] Universidade Federal de São Carlos (UFSCar), São Carlos, SP, Brasil

[b] Universidade de Coimbra, Coimbra, Portugal

\section{Resumo}

A discussão e a decisão de políticas públicas urbanísticas, especialmente planos diretores, devem contar com a participação dos cidadãos. Neste artigo, são discutidos alguns pontos referentes ao direito à participação popular nas políticas públicas urbanísticas, sem perder o foco no direito urbanístico a ele associado. A pesquisa foi desenvolvida a partir do método hermenêutico, por meio do levantamento e da análise das normas jurídicas aplicáveis ao planejamento urbano e à participação cidadã. Realizou-se a coleta de informações por intermédio de materiais bibliográficos, livros e periódicos. São ressaltadas algumas condições que resultaram na inserção atual da participação da população no planejamento urbano no Brasil. Analisando aspectos do direito urbanístico estabelecidos na Constituição de 1988 e abrangendo ferramentas do Estatuto da Cidade, como o plano diretor, os autores discutem a participação popular na gestão democrática das cidades. Encerra-se com reflexões sobre a política urbana brasileira, analisando-se a importância da concretização dos planos diretores participativos, tendo em vista o contexto vigente de escassa atuação popular na elaboração, execução e fiscalização do cumprimento dos instrumentos de planejamento.

Palavras-chave: Estatuto da cidade. Plano diretor. Participação popular. Gestão democrática. Direito urbanístico.

\section{Abstract}

Citizens should be active participants in the discussion and decision of the urban public policy, especially within Master Plans. This article discusses some issues regarding the public participation in the democratic management of cities, without losing the focus on urban law associated to it. The research was developed

CMO é jurista, doutor em Ciências da Engenharia Ambiental, e-mail: celmaran@gmail.com DL é jurista, doutora em ciências jurídico políticas, e-mail: dulce.rdgr@gmail.com ICNS é gestora e analista ambiental, mestra em engenharia urbana, e-mail: sousa.isabelnunes@gmail.com

\footnotetext{
${ }^{1}$ Processo no 2016/14163-7 da Fundação de Amparo à Pesquisa do Estado de São Paulo (FAPESP). "As opiniões, hipóteses e conclusões ou recomendações expressas neste material são de responsabilidade do(s) autor(es) e não necessariamente refletem a visão da FAPESP".
} 
according to the hermeneutical method, through the survey and analysis of the legal rules applicable to urban planning and citizen participation. Data were collected through bibliographic materials, books and periodicals. We highlight some conditions that resulted in the current insertion of the population's participation in Brazil urban planning process. Analyzing aspects of the urban law established in the 1988 Constitution, and covering City Statute tools such as the Master Plan, the authors discuss public participation in the democratic management of cities. The article finalizes with reflections on Brazilian urban policy, analyzing the importance of promoting Participatory Directors Plans, given the current context of scarce popular action in the drafting, implementation and monitoring of compliance of planning instruments.

Keywords: City statute. Master plan. Popular participation. Democratic management. Urban planning law.

\section{Introdução}

Os instrumentos e as ferramentas de gestão democrática da cidade, regulamentados pelo Estatuto da Cidade (Brasil, 2001), ampliaram a participação cidadã, aproximando o poder público da população no que concerne à construção das cidades. Tais mecanismos somente se efetivaram por meio da combinação entre democracia representativa e democracia direta, modelo adotado no Brasil que dá suporte à participação pública em várias áreas, entre elas a do planejamento urbano.

Porém, esse processo de aumento da participação, defendido por aparatos, como o Estatuto da Cidade e, consequentemente, os planos diretores, não impediu a elaboração de muitos planos alienados da realidade, ineficazes, tecnocráticos e, por vezes, até autoritários (Cordovil \& Rodrigues, 2010; Villaça, 1999), em que a participação popular era subjugada ou inexistente. Tais planos eram realizados por técnicos e especialistas, sem qualquer diálogo com a realidade das cidades e de seus habitantes e em flagrante desrespeito à legislação cabível.

Neste artigo, é discutido o direito à participação popular na gestão democrática das cidades, sem perder o foco no direito urbanístico a ele associado. Iniciando a abordagem com algumas condições que resultaram na atual situação da população no planejamento urbano brasileiro e atentando para o aspecto histórico do desenvolvimento da luta pela Reforma Urbana, abordam-se os dispositivos que nortearam a democracia participativa no urbanismo. Com uma abordagem em concordância com a realidade atual, encerra-se com reflexões sobre a política urbana brasileira, analisando-se a importância dos planos diretores participativos, tendo em vista a superação do atual contexto de escassa atuação popular na elaboração, execução e fiscalização do seu cumprimento.

\section{Notas iniciais sobre planejamento urbano}

Por ser produto e meio de produção social, o espaço urbano reflete a dimensão da desigualdade na distribuição de riquezas (Balbim, 2016). Tem-se a cidade como objeto de acumulação e de reprodução capitalista, concentradora de pobreza e de vulnerabilidades sociais pela exclusão e segregação socioespacial.

Assim, se, nos primórdios da urbanização (tardia) brasileira, o desenvolvimento dos núcleos urbanos advinham da expulsão do campo pela redução dos empregos em função da mecanização e da transformação do solo agrícola em reserva de valor (Dowbor, 2016), atualmente o mesmo modelo de valorização se repete nos ambientes urbanizados, na produção das cidades como mercadorias, em um ambiente favorável ao surgimento e à reprodução de uma nova forma de geração de riqueza, fundamentada na especulação imobiliária e no valor associado à escassez da terra.

Por conseguinte, na complexa e dinâmica produção social do espaço, o planejamento urbano insere-se como um dos domínios de intervenção mais importantes das autoridades públicas, com os planos diretores sendo os instrumentos que, de forma mais detalhada, definem as regras de uso, ocupação e transformação dos solos urbano e rural.

É por intermédio do planejamento urbano que se consegue passar de um paradigma assente na decisão de pretensões individuais (continuidade e manutenção de interesses privados) para um modelo de conformação jurídico-pública das variadas pretensões existentes, tendo em consideração interesses públicos e privados (de interessados, por exemplo, no acesso à moradia e na regularização fundiária). Somente com processos participativos é possível conceber "[...] uma cidade constituída não apenas para maximizar a 
reprodução do capital, mas também feita por - e para os - cidadãos" (Balbim, 2016, p. 130).

Logo, não é de se admirar que a relevância do planejamento urbano seja diretamente proporcional ao acréscimo de intervenções estatais, já que o surgimento de novas atribuições do Estado, nomeadamente de promoção de uma ordenada ocupação e desenvolvimento do território, foi acompanhado pelo aperfeiçoamento de mecanismos jurídicos, com o intuito de "[...] lidar de maneira mais justa com as forças de acumulação capitalistas [...]" (Balbim, 2016, p. 130).

Em um contexto de assimetrias de poder e divisão de ambições sobre a gestão urbanística - com a cidade como palco de disputas e de polarização entre seus grupos componentes e com a centralização da questão urbanística no fundiário e no imobiliário (Maricato, 2013) —, o planejamento urbano se notabiliza com a participação popular e a incorporação dos movimentos sociais.

De fato, é por via do planejamento urbano com vistas à equidade social que se procede, dominantemente, à tarefa de ponderação dos vários interesses, públicos e privados, uma vez que a opção por um modelo de ocupação do território, dentre as múltiplas alternativas possíveis, depende de uma justa ponderação de interesses que limite a amplitude discricionária de que, ab initio, goza a Administração (Oliveira, 2011). Essa ponderação segue um modelo procedimental a que a entidade competente, atuando coordenadamente com as demais entidades e acolhendo as manifestações de participação dos interessados, tem de dar cumprimento, para, no final, atingir uma decisão de planejamento.

Esse modelo inclui levantamento e identificação dos interesses públicos e privados, análise e ponderação desses interesses entre si e hierarquização deles no caso concreto (com utilização de critérios materiais de ponderação), o que impõe um efetivo reconhecimento e concretização do direito à participação popular em todas as suas dimensões, para todos os sujeitos afetados pelo plano (Rodríguez de Santiago, 2000).

\section{A evolução da participação popular no planejamento urbano brasileiro}

Após a instauração do período autoritário no regime militar, foi criado, em 21 de agosto de 1964, o Serviço Federal de Habitação e Urbanismo (SERFHAU) pela Lei no 4.380, em decorrência do processo de institucionalização do planejamento urbano no Brasil, iniciado nos anos de 1930.

As atribuições do SERFHAU compreendiam desde promover pesquisas e estudos relativos ao déficit habitacional, aspectos do planejamento físico, técnico e socioeconômico da habitação, até assessorar os municípios na elaboração ou adequação de seus planos diretores (Mota, 2007; Vizioli, 1998).

Nesse período de atuação do SERFHAU, assinala-se a desconsideração das especificidades dos municípios, com muitas críticas à ineficácia da metodologia de diagnóstico dos problemas urbanos, que legava exclusividade aos técnicos e especialistas a confecção dos planos locais (Villaça, 1999), cabendo à população desempenhar uma atitude meramente passiva (enquanto destinatários da ação administrativa) perante o planejamento e a gestão das cidades (Antonello, 2013).

A habitação era o tema central na Lei no 4.380 , com o plano diretor apoiado nesta, e o planejamento urbano era como um todo em segundo plano. O SERFHAU seguia um planejamento urbano considerado tecnocrático (Ferreira, 2007), sendo o responsável pela possibilidade de contratação de empresas privadas que auxiliavam a prefeitura, prestando consultoria para a elaboração de planos diretores (Vizioli, 1998), algo subsistente até hoje (Schvarsberg, 2013a).

Nas décadas de 1960 e 1970, o planejamento urbano no Brasil tinha o epicentro nos planos diretores como instrumentos de controle político, visto que o repasse de verbas estava condicionado à existência dos planos, financiados pelo SERFHAU. Tais medidas resultaram na elaboração de um grande número de planos diretores nas grandes e médias cidades à época (Feldman, 2005; Muniz, 2006). Segundo Araújo (2006), os planos diretores das décadas de 1960 e 1970 eram concebidos por técnicos e especialistas que elaboravam normas dissonantes do conjunto de fatores que influenciam e condicionam decisivamente a ocupação e a utilização dos espaços urbanos.

Efetivamente, com a criação da SERFHAU, não havia a garantia da participação da sociedade e dos usuários dos serviços públicos, resultando, obviamente, na ausência de uma democracia participativa, além da aprovação de propostas de planos irreais e, sem surpresa, ineficazes (Schvarsberg, 2013a).

Com o declínio do regime militar na década de 1980, a articulação de atores sociais e a adesão da população anteriormente excluída do processo de construção da política urbana - impulsionada pelos 
movimentos populares que exigiam liberdades políticas à sociedade - , tomou forma a luta por um novo marco para a política urbana, que emergiu ainda na década de 1960 (Marguti et al., 2016) e concretizou-se com a aprovação da Emenda Constitucional de Iniciativa Popular de Reforma Urbana no Congresso - Emenda Popular no 63, de 1987 (Cardoso, 2010), uma proposta de lei produzida pela sociedade civil (Antonello, 2013), alicerçada na busca pela gestão democrática e participativa da cidade, justiça e equidade social.

Inicialmente voltada para a luta pela melhoria de problemas locais, como a demanda por habitação, gradualmente a busca pela Reforma Urbana incorporou esforços para reversão das iniquidades sociais, com um escopo mais abrangente de exigências adicionadas ao final do regime militar (Saule \& Uzzo, 2009).

Os movimentos populares que conduziram a Reforma Urbana compunham-se de um heterogêneo grupo de pessoas, que trabalhou em diferentes aspectos do urbanismo com o propósito de atrelar a participação popular à politização dos problemas urbanos, com a difusão de processos participativos na elaboração de políticas públicas.

Ademais, diversas organizações da sociedade civil, movimentos sociais, associações profissionais, ONGs e uniões de classe se reuniram para tal propósito reformista, incluindo: Instituto de Arquitetos do Brasil (IAB), Federação Nacional dos Arquitetos, Federação Nacional dos Engenheiros, Federação de Assistência Social e Estabelecimentos de Ensino (FASE), Associação Nacional do Solo Urbano (ANSUR), Federação das Associações de Moradores do Estado do Rio de Janeiro (FAMERJ), entre outros movimentos sociais e de luta pela moradia (Saule \& Uzzo, 2009).

Esses integrantes tiveram papel essencial ao lançar as bases do planejamento urbano e de sua caraterização como uma das dimensões do Estatuto da Cidade. Ao abranger as diversas formas de organização do povo em sua luta pela libertação popular, tanto na cidade como no campo, incluíram-se realidades diversificadas, como a das associações de bairros, dos grupos de loteamentos clandestinos e ocupações tidas como irregulares, das comunidades de base, dos grupos organizados em função da luta pelo acesso à terra e à moradia, entre outras formas de lutas e de organizações populares, e dos movimentos sindicais, exigindo que sua voz fosse ouvida e sua representação fosse assegurada (Mance, 2007).
Eram movimentos e grupos que, por estarem solidamente organizados em eixos de defesa de interesses comunitários, contribuíram para a previsão jurídica da transição de "[...] uma sociedade governada por 'representantes' para um sistema no qual a participação direta do cidadão adquire um peso muito mais importante [...]" (Dowbor, 2016, p. 31).

Como resultado dessa proposta e das exigências sociais especialmente ligadas à necessidade de reestruturação da propriedade fundiária, obteve-se a inserção dos artigos 182 e 183 na Constituição Federal, futuramente regulamentados pelo Estatuto. Além de colocar em pauta a participação da população no planejamento urbano, essa medida finalmente trouxe consigo a previsão constitucional sobre as questões urbanas no Brasil (Costa \& Favarão, 2016).

Posteriormente, os planos diretores da década de 1990 passaram a ser desenvolvidos por meio de instrumentos urbanísticos inovadores, presentes no capítulo da política urbana, conforme preceitos estabelecidos na Constituição de 1988. Ainda que o caráter tecnocrático prevalecesse, houve um grande esforço no sentido de incrementar a participação popular, mesmo que esta não fosse legalmente garantida na elaboração dos planos diretores daquele período. Tais esforços - mobilizados por órgãos públicos, equipes acadêmicas, sociedade civil organizada e movimentos sociais - foram essenciais para que a Reforma Urbana se fortalecesse, com a posterior aprovação do Estatuto da Cidade.

Paralelamente ao "[...] efervescente momento jurídico-institucional desse período inicial da redemocratização brasileira [...]" (Costa \& Favarão, 2016, p. 111), ocorreu a II Conferência das Nações Unidas para Assentamentos Humanos (Habitat II), realizada em Istambul, Turquia, em 1996. A agenda final da conferência consistia em apontamentos sobre a

[...] necessidade de provisão de moradias adequadas para todos, de se assegurar o desenvolvimento sustentável dos assentamentos precários como condição para qualidade de vida, e de garantir a participação democrática [...] (Costa \& Favarão, 2016, p. 112).

Com a legitimação do Estatuto da Cidade — projeto de lei (Brasil, 1990) que tramitou por 10 anos e foi sancionado 13 anos após a promulgação da Constituição Federal - , uma nova concepção de plano diretor passou a ser aplicada, embasada na gestão participativa 
do espaço urbano, proporcionando o "[...] respaldo jurídico para planejamento e gestão democráticos das cidades [...]" (Antonello, 2013, p. 242).

Com a aprovação do Estatuto da Cidade, houve, na década de 2000, evidências da importância da formulação de políticas urbanas pautadas na participação social, com avanços na adoção de iniciativas inclusivas e dialogadas no planejamento territorial, de modo a fortalecer a gestão democrática, a promoção do direito à cidade (direito de uso e apropriação) e sua função social.

Acresce que um novo órgão destinado ao desenvolvimento do planejamento urbano no Brasil foi criado em 2003. Originado do Decreto no 4.665 , o Ministério das Cidades é um órgão da administração federal que reforçou, do ponto de vista institucional, o papel do urbanismo no âmbito das políticas públicas.

A criação do Ministério veio para "[...] ocupar um vazio institucional que retirava completamente o governo federal da discussão sobre a política urbana e o destino das cidades [...]" (Maricato, 2006, p. 214), já que, desde o regime militar, nenhuma proposta de política urbana conseguiu ser implementada nos municípios (Schvarsberg, 2013a).

Em busca da adoção de uma estratégia que imprimisse um novo caráter à elaboração e à implementação dos planos diretores, foi adotada a denominação "Planos Diretores Participativos" pelo Ministério das Cidades, trazendo uma ressignificação aos planos e diferenciando-os, assim, dos Planos Diretores de Desenvolvimento Integrado (PDDIs), associados tipicamente aos planos da década de 1960 (Schvarsberg, 2013a). Essa estratégia procurou evidenciar a nova abordagem dispensada aos planos diretores, mais receptiva e acessível à população e mais próxima dos ideais da democracia participativa, sendo efetivada por meio da Campanha Nacional "Plano Diretor Participativo: Cidade de Todos" (Oliveira \& Moreira, 2006).

Complementarmente, a necessidade de formulação de uma Política Nacional de Desenvolvimento Urbano (PNDU) no âmbito do II Plano Nacional de Desenvolvimento (PND) decorreu da ausência de propostas de política urbana que fossem efetivadas após 1985, ocasionando o desencadeamento das Conferências das Cidades em 2003 e, posteriormente, em 2005, 2007, 2009, 2011 e 2013.

Por intermédio do Decreto no 5.790, foi instituído o Conselho das Cidades (ConCidades), “[...] amplo espaço de debate, de natureza consultiva e deliberativa [...]" (Marguti etal., 2016, p. 17), que, em suas atribuições, visa

[...] estimular a ampliação e o aperfeiçoamento dos mecanismos de participação e controle social, por intermédio de rede nacional de órgãos colegiados estaduais, regionais e municipais [...] (Brasil, 2006, art. 3o, inciso X).

Sendo considerada "instância de gestão democrática" no âmbito do Ministério das Cidades, o ConCidades também tem como atribuição “[...] promover a cooperação entre os governos e incentivar e fortalecer os conselhos afetos à política de desenvolvimento urbano nos três níveis de governo" (Santos \& Montandon, 2011, p. 17).

As resoluções aprovadas pelo ConCidades em reuniões ordinárias delineiam recomendações ao Ministério das Cidades no que diz respeito à política de desenvolvimento urbano. De todas elas, cabe destacar a Resolução no 25, que dispõe sobre o processo participativo na elaboração do plano diretor, o envolvimento do ConCidades ou similar nesse processo, a devida publicidade e a realização das audiências públicas.

As Conferências das Cidades, além de encontrarem normatização no art. 15 do Decreto no 5.790 (Brasil, 2006), também a encontram no inciso III do art. 43 do Estatuto da Cidade, constituindo-se em mais um mecanismo para garantia da gestão democrática sobre assuntos referentes à promoção da PNDU. 0 processo das Conferências das Cidades representa um seguimento participativo na escala nacional do planejamento urbano contemporâneo, com propostas debatidas em conferências municipais e estaduais.

\section{Democracia participativa e democracia representativa no urbanismo}

Nos tempos atuais, não é possível conceber, em função das dimensões geográficas e populacionais (Valente, 2006) e diante da estrutura institucional, territorial e social existentes, um Estado fundamentado apenas na democracia direta - aquela em que o poder é exercido diretamente pelo povo. No entanto, deve ser promovido, em sede de princípio, o respeito à vontade popular, equilibrando-se as instituições representativas e participativas. Assim sendo, não se pode pensar em atuação dissonante, com a desvinculação da democracia representativa em relação à democracia 
participativa. Elas devem atuar em coexistência e complementaridade (Santos \& Avritzer, 2005).

A defesa da necessidade de recorrer a uma hibridização dessas duas formas de democracia, com o surgimento de uma democracia combinada, baseia-se, para Valente (2006, p. 128), “[...] na clara perda de legitimidade, de credibilidade e de eficácia do sistema de democracia representativa [...]", que "[...] impõe o seu redimensionamento político com a agregação, por complementariedade, da dimensão participativa [...]", o que pode ser combatido pela influência do indivíduo, inserido no processo político e na formulação da agenda pública.

A ideia central de democracia participativa alicerça-se na autonomia política, em que: "[...] aqueles que estão submetidos às leis devem poder, de algum modo, participar dos processos de criação das leis às quais estão submetidos [...]" (Oliveira \& Araújo, 2007, p. 6634). Trata-se de uma concepção consonante com o que prevê o art. 1ํㅡㄹ parágrafo único, da Constituição, em relação à participação do povo, visto que o poder emana dele e é exercido por meio da representação eleitoral ou de forma direta. Acolhe, por conseguinte, os postulados das democracias representativa e participativa, nas quais predomina um processo dinâmico, que oferece aos cidadãos possibilidades de desenvolvimento integral, liberdade de participação crítica no sistema político e condições de igualdade econômica, política e social.

Esses dois elementos, representativo e participativo, devem estar integrados, visto sua complementaridade, de modo que órgãos representativos, eleições periódicas, pluralismo partidário, separação de poderes, figuras referendárias, iniciativas populares, orçamentos participativos, entre outros, assimilam-se à oferta de possibilidades efetivas de aprender a democracia e de participar nos processos de decisão (Canotilho, 2002), podendo atuar como substitutos parciais do processo de representação e de deliberação (Santos \& Avritzer, 2005).

Considerando a democracia semidireta, encontram-se positivados constitucionalmente o plebiscito, o referendo, a iniciativa popular e a legislação participativa (Garcia Navarro, 2005), além da ação popular na esfera jurisdicional (art. 14 da Constituição). Ampliando esse elenco constitucional, há os conselhos gestores e as audiências públicas (Brasil, 2000).

Tendo em vista as determinações constitucionais, qualquer tentativa de coibir ou diminuir a participação social nas questões relacionadas à gestão democrática constituiria em um atentado e em uma afronta aos comandos institucionais e, consequentemente, em uma forma de retrocesso nas conquistas e nos direitos adquiridos pela sociedade.

0 objetivo de atingir a igualdade baseada na gestão democrática e participativa também se alicerça na busca pela transparência na gestão pública, tornando-a acessível, prevenindo a corrupção e resguardando os interesses públicos em detrimento dos interesses privados (Ferreira, 2012). Contudo, para atingir essa meta de cidadania plena, é necessária a adequação do Estado para garantir a divulgação das formas de interferência da população no processo decisório.

A gestão democrática em uma sociedade com ampla diversidade e pluralidade requer a abrangência de múltiplos interesses, sendo apenas consideradas ou atingidas por meio do diálogo e da abertura governamental, em regra, as questões coletivas, além, é claro, da demanda da própria sociedade, ao exigir o direito de participar do processo de elaboração e aplicação das políticas públicas, algo possível de conseguir somente por meio de uma sociedade civil organizada e com cidadãos informados e mobilizados.

A ideia de propiciar o atendimento aos anseios da população por meio da participação e da gestão democrática e, com isso, assegurar diversos direitos sociais “[...] busca conferir transparência e eficácia à política, promovendo o controle social como garantia de uma gestão proba [...]" (Ferreira, 2012).

Os sujeitos, que são simultaneamente destinatários da política pública de planejamento e de gestão das cidades, são de variada ordem (proprietários de terra, movimentos sociais, plataformas de interesses difusos, utilizadores de serviços) e transportam consigo diversos interesses, nem sempre convergentes entre si, pelo que é necessário proceder a uma devida ponderação entre eles e orientar essa ponderação por critérios jurídicos e éticos, de modo a cumprir a função social do solo e da propriedade, sem esquecer a satisfação das necessidades básicas dos cidadãos.

A atuação da sociedade no planejamento e na gestão das cidades deve, de fato e por direito, ocorrer em todos os momentos, desde a contribuição para os técnicos oferecerem soluções ajustadas à realidade social e aos verdadeiros anseios da comunidade até o momento de aprovação, execução, avaliação e monitorização das políticas públicas urbanísticas. Para tanto, deve haver uma mudança nos padrões receptivos adotados 
pelos técnicos, que, muitas vezes, somente apresentam os resultados de seus trabalhos de planejamento de forma a informar a população, sem possibilidade de uma ampla discussão que permita a colaboração ativa desta nas políticas a serem criadas, bem como exige uma mudança de comportamento do poder político, o qual deve atuar para possibilitar ferramentas reais e efetivas para que os cidadãos integrem o grupo de atores que influenciam e participam na tomada de decisões municipais.

\section{O estatuto da cidade e a participação popular}

As maiores contribuições do Estatuto da Cidade redundaram na busca pela democratização do solo urbano (Lima \& Sá, 2014) por meio, principalmente, da regulamentação de diversos instrumentos jurídicos e urbanísticos de ordenação do uso e ocupação do solo e por via da determinação da participação popular na gestão das cidades, no intuito de garantir uma democracia participativa e inclusiva na aplicação da política urbana.

Assim, os arts. 43 a 45 do Estatuto dispõem sobre a participação popular nos planos diretores por intermédio de quatro instrumentos para garantia da gestão democrática, quais sejam: os órgãos colegiados de política urbana nos níveis nacional, estadual e municipal; os debates, as audiências e as consultas públicas; as conferências sobre assuntos de interesse urbano nos níveis nacional, estadual e municipal; e a iniciativa popular de projeto de lei e de planos, programas e projetos de desenvolvimento urbano (Brasil, 2001).

Devido à ressignificação do plano diretor pelo Estatuto da Cidade, tem-se que este deve ser construído, obrigatoriamente, por meio de uma gestão participativa com o intuito de alcançar as funções sociais da cidade e da propriedade, com a prevalência dos interesses coletivos sobre os individuais ou mesmo sobre determinados grupos (Schvarsberg, 2013b).

Com a democratização das decisões no planejamento das cidades, possibilita-se que a população participe ativamente das políticas públicas urbanísticas, conforme previsto no inciso II do art. $2^{\circ}$ do Estatuto (Brasil, 2001). Dessa maneira, adiciona-se algo totalmente inovador ao direito urbanístico brasileiro, com vistas ao controle social da população sobre as decisões municipais, por meio do compartilhamento e da delegação de poderes quanto ao futuro de toda uma comunidade.

O Estatuto da Cidade abre importantes perspectivas no que se refere ao controle social sobre o processo de planejamento urbano. Conforme relatório do Programa das Nações Unidas para os Assentamentos Humanos, das inovações contidas no Estatuto da Cidade, tem-se uma nova abordagem para o plano diretor, a qual inclui a participação da sociedade (UN-HABITAT, 2014).

O Estado desempenha um papel primordial no processo de efetivação dos direitos fundamentais, elaborando e gerenciando políticas públicas para concretização destes. Todavia, esse papel estatal não logra êxitos se concebido de modo a não garantir a participação popular na gestão do direito à cidade sustentável. De fato, a participação pública passa a desempenhar uma indispensável função de

[...] criação de uma dinâmica coletiva na cidade, pautada na tentativa de eliminar a imposição técnica vinculada ao poder governamental e construir um conhecimento comum da cidade [...] (Antonello, 2013, p. 245).

Com isso, visa-se alcançar um processo dialogado de democratização das decisões públicas, sendo defensável que também o direito à participação pública seja considerado um direito fundamental de ranking constitucional. Em Portugal, por exemplo, o direito à participação pública é configurado como análogo aos direitos, às liberdades e às garantias, recebendo o mesmo tratamento constitucional destes (Correia, 2012).

Evidenciam-se as vantagens da participação popular na constatação de Habermas (1997), que aponta que o cidadão, quando participa da formação do processo decisório no domínio das normas urbanísticas locais, não se sente simplesmente um destinatário da norma jurídica, mas um partícipe na elaboração legislativa. Por conseguinte, é imprescindível que as pessoas se envolvam no processo de decisões relativas ao planejamento urbanístico, visto que as decisões públicas compartilhadas com os seus destinatários são cumpridas com mais empenho e menos resistência.

Em suma, a participação pública apresenta como benefício o acolhimento dos interesses coletivos, o que possibilita o ajustamento da atuação da administração pública às efetivas necessidades da população: econômicas, sociais, ambientais, entre outras. Essa estratégia de gestão inclusiva proporciona 
também a democratização e a legitimação da atuação administrativa, além de impulsionar a formação da consciência cívica e política da sociedade em suas relações com o poder público.

Tem-se na participação um "elemento legitimador da ação regulatória do Estado" (Oliveira \& Vasconcellos, 2011, p. 7), bem como a oportunidade de uma reflexão crítica da realidade a partir desta, com o acolhimento e o compartilhamento da responsabilização sobre o público e os interesses coletivos, evitando privilégios a grupos restritos da sociedade e auxiliando no combate à corrupção.

No que se refere às formas de intervenção da população no âmbito do planejamento, há várias classificações possíveis. A que melhor demonstra a pluralidade de meios de participação pública refere-se à intensidade de intervenção dos cidadãos no planejamento.

Os cinco níveis de relevância da intervenção dos indivíduos nos procedimentos de planejamento são: o direito de informação procedimental dos interessados; a participação em sentido estrito ou participação-audição no procedimento de elaboração — bem como de revisão ou de alteração — dos planos urbanísticos; a participação-negociação, concretizada na tarefa de concertação dos interesses envolvidos na ocupação do território; a admissibilidade de instrumentos de planejamento de iniciativa privada; e, por último, a promoção da contratualização das soluções jurídico-urbanísticas a adotar, bem como sua execução (Oliveira et al., 2016).

As diferentes intensidades de participação dos interessados nos procedimentos de tomada de decisão administrativa, a respeito da metáfora da "escada da participação" de Arnstein (1969), têm no degrau mais baixo a ausência de participação, nos degraus intermediários a informação ou consulta dos interessados para a tomada de decisão final por parte das entidades públicas e no degrau mais elevado o poder de codecisão sobre assuntos que lhes dizem respeito.

Não basta, por isso, conceber como modelo participativo o simples acesso às informações e aos documentos decorrentes dos trabalhos de elaboração ou de revisão do plano diretor, realizados pela equipe técnica, ou mesmo que os cidadãos sejam meramente consultados. É preciso que os munícipes possam participar do processo deliberativo, com poder de decisão, em uma forma representativa social ou mesmo individual. Defende-se, portanto, que, por se tratar do estabelecimento de políticas públicas, deve ocorrer a participação democrática em todas as fases, em especial na tomada de decisão.

Por meio de planos diretores participativos é que se alcança mais facilmente a funcionalidade social das cidades, com reflexos positivos da urbanização para todos os munícipes. Esses reflexos benéficos vão propiciar aos cidadãos um Estado de bem-estar, absolutamente essencial para o exercício de seus direitos fundamentais.

\section{Reflexões sobre a política urbana brasileira}

Ainda que, na Constituição de 1988, tenham sido criadas as "[...] bases jurídicas e institucionais para uma participação maior dos poderes locais na gestão dos recursos do país [...]", com previsão de “[...] formas de participação direta, ao lado do sistema formal de representação [...]" (Dowbor, 2016, p. 29), tem-se uma vigente ruptura entre as aspirações populares e as decisões dos dirigentes que representam a sociedade.

Essa contradição justifica-se pela organização político-partidária em voga, com destaque para “[...] as posições dos grandes grupos econômicos [...]" (Dowbor, 2016, p. 30) e a expressão insuficiente dos anseios político-partidários da população em geral. Esse fato evidencia a existência de uma divisão da sociedade brasileira, com representantes governando para uma minoria, em que políticos não representam os interesses do eleitorado como um todo, desprezando os interesses do coletivo.

Todavia, a abertura à participação pública, possibilitada pelo Estatuto da Cidade, é considerada um progresso do Estado contemporâneo, que transitou de um sistema fechado, no qual a participação (e a informação) pública não correspondia senão a uma "poluição" da democracia, para um modelo consonante às exigências de uma nova governança pública (Jégouzo, 2007).

0 Estatuto é reconhecido internacionalmente, conferindo ao Brasil a reputação pela inovação no desenho urbano, no planejamento e na governança, algo possibilitado pelo engajamento dos movimentos sociais e pela capacidade institucional e de planejamento dos governos locais (UN-HABITAT, 2014).

No entanto, o "amplo repertório de instrumentos participativos" previstos no Estatuto da Cidade, segundo Avelino (2016, p. 146), "não traz consigo orientações sobre as articulações dos mesmos”, e, 
“[...] com raras exceções, a legislação sobre política urbana não prevê qualquer relação entre estes instrumentos". Para o autor mencionado, apesar de ser um aspecto positivo da política, já que possibilita diferentes formas de intervenção, a diversidade de instrumentos, quando desprovida de coordenação, "[...] traduz-se em isolamento e fragmentação, o que não contribui para a efetividade dessa participação [...]" (Avelino, 2016, p. 147).

Quanto ao plano diretor municipal, instrumento de ordenamento urbanístico básico da política de desenvolvimento e de expansão urbana, é de se esperar pelo menos sua elaboração nos municípios obrigados a fazê-lo após 15 anos de aprovação do Estatuto da Cidade.

Não podendo ser utilizada como forma de aferir os avanços das políticas urbanas no Brasil, mas sendo capaz de ilustrar um panorama quantitativo da situação dos planos diretores municipais no país, a Pesquisa de Informações Básicas Municipais (MUNIC) (IBGE, 2016) traz dados sobre a porcentagem de municípios brasileiros que contavam com plano diretor (concretizado ou em processo de realização) em 2015, ilustrando o impacto que o Estatuto da Cidade exerceu na elaboração de planos diretores municipais.

Conforme dados da pesquisa citada, 50\% (2.786) dos municípios brasileiros possuíam plano diretor em 2015, valor igual ao apurado em 2013 e superior ao encontrado em 2005 (14,5\%). Ademais, 12,4\% (691) dos municípios encontravam-se elaborando o plano e 37,6\% (2.092) não possuíam plano diretor.

Como muitos municípios não têm obrigação legal de formular seu plano diretor por possuírem menos de 20 mil habitantes, destaca-se que, dos 1.742 municípios "que necessitavam elaborar o plano diretor, conforme previsto no Estatuto das Cidades, restaram $188(10,8 \%)$ que ainda não o haviam feito. Destes, no entanto, 92 (5,3\%) afirmaram que o Plano estava em elaboração" (IBGE, 2016).

Para Marguti et al. (2016, p. 18), o pressuposto de necessidade de detalhamento e de regulamentações posteriores para aplicação dos instrumentos do Estatuto da Cidade nos planos diretores torna-se empecilho à viabilização destes, visto que a descontinuidade das gestões municipais desencoraja a "[...] elaboração de leis complementares para a efetiva operacionalização dos instrumentos [...]", além de que, frequentemente, "[...] a maneira como os instrumentos devem incidir sobre o território está disposto de maneira deficiente nos planos [...]" (Costa \& Favarão, 2016, p. 121), deixando a programação e a operacionalização de normas posteriores cuja adoção é puramente eventual, não contando com participação popular.

Constata-se também uma realidade de aprovação de diversos planos diretores não implementados ou sem que vários dos instrumentos previstos no Estatuto da Cidade tenham sido incorporados, e, por diversas vezes, quando tais instrumentos são incorporados, não se encontram relacionados ao território (Santos \& Montandon, 2011) ou não estão em conformidade com a capacidade de gestão do município (Costa \& Favarão, 2016).

Vislumbra-se um quadro de incapacidade técnica, política e institucional de muitos municípios, inaptos a desenvolver "[...] estudos e diagnósticos consistentes para compreender a demanda de sua população de maneira a orientar o planejamento [...]" (Marguti et al., 2016, p. 18), assim como programas e projetos que proponham soluções aos variados problemas urbanos existentes.

Além disso, ainda é recorrente a ausência de "[...] articulação entre os dispositivos do plano diretor e o planejamento orçamentário [...]" municipal, imprescindível à sua concretização (Marguti et al., 2016, p. 18), concomitante à limitada quantidade de municípios que efetivamente adotam mecanismos para incremento da arrecadação e distribuição dos recursos no espaço urbano e à indução do desenvolvimento urbano, como o IPTU progressivo no tempo.

Ainda dentro dessas questões financeiras e administrativas, destaca-se o notório "[...] avanço no sentido da descentralização e da ampliação das competências legais transferidas [...]" (Costa \& Favarão, 2016, p. 118), no que concerne ao reconhecimento do município como ente federado pela Constituição Federal brasileira, em relação aos recursos para operar as políticas urbanas, que não foram necessariamente gerados ou transferidos. Há, portanto, problemas "[...] no campo do fortalecimento institucional, no acesso a recursos técnicos e financeiros, notadamente nos pequenos municípios [...]" (Costa \& Favarão, 2016, p. 122).

Com relação à adoção de mecanismos que possibilitam uma participação popular maior (como conselhos, conferências e consultas públicas), tem-se uma realidade de realização de cinco conferências nacionais das cidades, em 2003, 2005, 2007, 2010 e 2013 (Souza et al., 2013). Complementarmente, "[...] o 
percentual de municípios com conselhos passou de $4 \%$, em 1996 , para $24 \%$, em 2006 , e para $64 \%$, em 2012 [...]" (IPEA, 2016, p. 75).

Entretanto, ainda imperam formas de participação popular restritas ao caráter consultivo e informativo, $\mathrm{e}$, frequentemente, os conselhos municipais (como os de saúde e de educação)

[...] apresentam contradições, pois são espaços políticos de representação e de aprendizagem coletiva, mas podem também simplesmente reafirmar as práticas fisiológicas ou de monopolização/legitimação dos interesses [...] (Schneider \& Campos, 2015, p. 15).

Ademais, como a "[...] produção do espaço urbano encontra-se intimamente relacionada e até mesmo subjugada às lógicas de acumulação do capital [...]" (Balbim, 2016, p. 163), o direcionamento de decisões a serviço de interesses políticos e particulares por meio do atendimento à demanda de grupos mais organizados da sociedade tornou-se prática recorrente. Verificam-se, destarte, a cooptação política nas instâncias decisórias e a ampla participação de representantes governamentais e grupos econômico-empresariais ligados ao setor imobiliário, o que acarreta na manipulação das instâncias participativas e na possível restrição à participação popular (Oliveira \& Vasconcellos, 2011).

\section{Considerações finais}

O Estado brasileiro passou por um período de imposição estatal para elaboração de planos diretores municipais por questões meramente orçamentárias, tendo como protagonistas as equipes técnicas, sendo fatores que antecederam à previsão constitucional de política urbana e que não contemplavam o cidadão como importante ator na construção dessa política pública.

No período ditatorial, em que reinava a abundância de planos diretores tecnocráticos, a despolitização da agenda pública esteve presente, com o cidadão apenas acatando decisões e impedido de externar opiniões, restrito ao mero acolhimento de determinações das autoridades.

Posteriormente, com a Reforma Urbana, o advento do Estatuto da Cidade e de instituições relacionadas ao planejamento urbanístico, houve início um novo momento na sociedade brasileira, com a inclusão dos cidadãos nas discussões das políticas urbanas, especialmente planos diretores, com claros avanços na adoção de iniciativas inclusivas e dialogadas no ordenamento territorial, fortalecendo, assim, a gestão democrática e a funcionalidade social das cidades brasileiras.

Passou-se de um processo conduzido com métodos autoritários e tecnocráticos para um modelo inclusivo, descentralizado e participativo, com controle social sobre o planejamento urbanístico, visando que o exercício da cidadania ultrapassasse o momento eleitoral e alcançasse o acompanhamento contínuo das ações do governo.

No entanto, com a participação democrática praticamente limitada às eleições periódicas e ao voto, restringindo o necessário exercício permanente da fiscalização dos processos de tomada de decisões governamentais, surgiu a demanda por um novo modelo. Por conseguinte, em uma sociedade tão plural como a brasileira, era de se esperar a coexistência e a complementaridade de modelos democráticos representativos e participativos, como forma de garantir certa descentralização estatal, na busca pela defesa dos interesses dos cidadãos no que concerne ao atendimento da agenda política.

Visando à concepção de uma gestão pública mais concordante com as vontades, exigências, prioridades e pretensões dos cidadãos, o Estatuto da Cidade determinou a execução dos denominados planos diretores participativos, formulados com o apoio da população e visando abranger a percepção desta em relação à cidade almejada. Esse instrumento normativo visa ouvir as demandas da sociedade e atendê-las, respeitando o direito à participação dos cidadãos no processo decisório de construção da política urbana, não atrelado, necessariamente, ao paradigma da democracia representativa.

Após 15 anos de Estatuto da Cidade, esperava-se o cumprimento por parte dos municípios obrigados a elaborar planos diretores. Porém, não é isso que se vê nos dados apresentados. Municípios que se encontram desprovidos de plano diretor, mesmo no caso dos desobrigados legalmente, perderam um foro fundamental de discussão de forma democrática de suas políticas públicas urbanísticas.

A imposição da participação popular na concepção do plano diretor, assegurada pelo Estatuto da Cidade, inova no sentido de não restringir o planejamento da cidade à esfera técnica, ao tornar acessível às diversas camadas sociais o direito de contribuírem e associarem-se na busca por uma sociedade mais 
consciente e justa, rompendo com a tradição excludente, frequentemente encontrada na gestão pública.

Ainda há muito que se avançar, visto que, mesmo em muitos municípios que cumpriram com a obrigação de implementação do plano diretor, constata-se uma tênue participação democrática, dada a fragmentação da legislação e a fragilidade na sua aplicação, além da dispersão de competências e do excessivo caráter tecnocrático dos planos (ainda em voga em diversos municípios), que, muitas vezes, refletem situações distantes da conjuntura municipal, demonstrando o despreparo e a inépcia de muitos governos locais na análise e na interpretação do próprio território.

Adicionalmente, constata-se o esvaziamento das instâncias participativas e decisórias, em decorrência da percepção (acurada) de que as opiniões expressas nem sempre são consideradas, visto a instauração de instâncias decisórias "de fachada”, existentes apenas para constar no processo de elaboração dos planos diretores, mas carentes de efetividade ou de relevância para os responsáveis pelas decisões governamentais.

A ausência de um modelo de condução da participação nas instâncias locais é também prejudicial, assim como a desconsideração das particularidades locais no planejamento e no ordenamento territorial, o distanciamento de funções de planejamento e de execução, tornando inviável a aplicação de diversas estipulações técnicas presentes nos planos aprovados, carência que poderia ser sanada com a oitiva dos que vivenciam a cidade cotidianamente.

Tais fragilidades na participação popular acarretam na desmobilização dos atores sociais e na inoperância dos planos diretores, tornando-os meras formalidades, distantes dos anseios da sociedade e concernentes às pretensões das elites que almejam a manutenção do status quo.

Por conseguinte, os avanços do período democrático trouxeram efeitos normativos, institucionais e formais em relação à política urbana. Trata-se, no entanto, de conquistas legais insuficientes, resultados incipientes que não se concretizaram de forma completa na esfera executiva, com nítidas defasagens na efetividade dos canais de participação.

A inclusão de segmentos populares — todos eles — nos processos decisórios aproxima-se da aspiração por um horizonte distante dos moldes de reprodução da exclusão e das injustiças sociais. Sendo assim, os administradores públicos devem envolver a população na discussão dos assuntos públicos, seja por meio de representação com poder de decisão, seja viabilizando a atuação direta dos munícipes nos foros de discussão.

Contudo, esse almejado envolvimento popular não se viabilizará tão cedo caso não ocorra o enfrentamento da questão fundiária, com reconhecimento da função social da terra e da cidade, e a desvinculação de alianças políticas embasadas meramente na compatibilidade com os interesses empresariais e de mercado.

Em um cenário ideal de gestão democrática e participativa das cidades, os planos diretores direcionam o crescimento sustentável em conformidade com as perspectivas dos cidadãos - desde que estas se concertem com o interesse público na correta ocupação do território - , sendo ferramentas que articulam a interferência da população na construção da cidade e que promovem boas práticas de planejamento urbano, precisamente aquelas que contribuem para a obtenção de um ambiente urbano sadio e equitativo, como é exigido pelo direito fundamental à cidade.

\section{Referências}

Antonello, I. T. (2013). Potencialidade do planejamento participativo no Brasil. Sociedade \& Natureza, 25(2), 239-254. http://dx.doi.org/10.1590/S1982-45132013000200003.

Araújo, M. E., Jr. (2006). Algumas considerações sobre o Plano Diretor dos municípios e sua importância no processo de construção da cidadania e da democracia. Revista do Direito Público, 1(1), 45-62. http://dx.doi. org/10.5433/1980-511.2006v1n1p45.

Arnstein, S. R. (1969). A ladder of citizen participation. Journal of the American Planning Association, 35(4), 216-224.

Avelino, D. P. (2016). Cidade e cidadania: considerações sobre a gestão democrática na política urbana brasileira. In M. A. Costa. O Estatuto da Cidade e a Habitat III: um balanço de quinze anos da política urbana no Brasil e a Nova Agenda Urbana (pp. 131-157). Brasília: IPEA.

Balbim, R. (2016). Diplomacia de cidades: agendas globais, acordos locais. In R. Balbim (Org.). Geopolítica das cidades: velhos desafios, novos problemas (pp. 123-170). Brasília: IPEA.

Brasil. (1990, 9 de outubro). Projeto de Lei $n^{\circ}$ 5.788, de 9 de outubro de 1990. Brasília: Senado. Recuperado em 15 de outubro de 2016, de http://www.camara.gov.br/ proposicoesWeb/fichadetramitacao?idProposicao $=21252$ 
Brasil. (2000, 4 de maio). Lei Complementar no 101, de 4 de maio de 2000. Estabelece normas de finanças públicas voltadas para a responsabilidade na gestão fiscal e dá outras providências. Brasília: Diário Oficial da União.

Brasil. (2001, 10 de julho). Lei no 10.257, de 10 de julho de 2001. Regulamenta os arts. 182 e 183 da Constituição Federal, estabelece diretrizes gerais da política urbana e dá outras providências. Brasília: Diário Oficial da União.

Brasil. (2006, 25 de maio). Decreto $n^{\circ}$ 5.790, de 25 de maio de 2006. Dispõe sobre a composição, estruturação, competências e funcionamento do Conselho das Cidades - ConCidades, e dá outras providências. Brasília: Diário Oficial da União.

Canotilho, J. J. G. (2002). Direito Constitucional e Teoria da Constituição (6a ed.). Coimbra: Almedina.

Cardoso, R. M. (2010). A iniciativa popular legislativa da Assembleia Nacional Constituinte ao regime da Constituição de 1988: um balanço (Dissertação de mestrado). Departamento de Direito, Pontifícia Universidade Católica do Rio de Janeiro, Rio de Janeiro.

Cordovil, F. C. S.; \& Rodrigues, A. L. (2010). Da tecnologia à participação popular: a institucionalização e os novos rumos do planejamento urbano em Maringá, Paraná, Brasil. Scripta Nova. Revista Electrónica de Geografía y Ciencias Sociales, 14(331), 1-15.

Correia, F. A. (2012). Manual de Direito do Urbanismo (4a ed., Vol. 1). Coimbra: Almedina.

Costa, M. A., \& Favarão, C. B. (2016). Institucionalidade e governança na trajetória recente da política urbana brasileira: legislação e governança urbanas. In M. A. Costa. O Estatuto da Cidade e a Habitat III: um balanço de quinze anos da política urbana no Brasil e a Nova Agenda Urbana (pp. 109-129). Brasília: Ipea.

Dowbor, L. (2016). Políticas urbanas e participação: o resgate da democracia pela base. In R. Balbim (Org.). Geopolítica das cidades: velhos desafios, novos problemas (pp. 25-54). Brasília: Ipea.

Feldman, S. (2005). Planejamento e zoneamento. São Paulo: Edusp/Fapesp.

Ferreira, M. (2007). Planejamento urbano nos tempos do SERFHAU: o processo de construção e implementação do plano diretor de desenvolvimento integrado de Franca (Tese de doutorado). Escola de Engenharia de São Carlos, Universidade de São Paulo, São Carlos.
Ferreira, V. C. S. (2012). Cidade e democracia: o espaço urbano, os direitos fundamentais e um novo conceito de cidadania. Âmbito Jurídico, 15(103). Recuperado em 21 de setembro de 2016, de http://www.ambito-juridico.com. br/site/?n_link=revista_artigos_leitura\&artigo_id=12143 Garcia Navarro, A. (2005). Democracia semidireta: referendo, plebiscito, iniciativa popular e legislação participativa. Revista de Informação Legislativa, 42(166), 9-22.

Habermas, J. (1997). Direito e Democracia: entre facticidade e validade (Vol. 1-2). Rio de Janeiro: Tempo Brasileiro.

Instituto Brasileiro de Geografia e Estatística - IBGE. (2016). Perfil dos municípios brasileiros 2015. Pesquisa de Informações Básicas Municipais (61p.). Rio de Janeiro: IBGE.

Instituto de Pesquisa Econômica Aplicada - IPEA. (2016). Governança urbana e legislação: questões e desafios para uma nova agenda urbana. In Instituto de Pesquisa Econômica Aplicada - IPEA. Relatório Brasileiro para a Habitat III (pp. 69-80). Brasília: ConCidades, IPEA.

Jégouzo, Y. (2007). Principe et idéologie de la participation. In D. Amirante, M. Bayle, L. B. Chazournes, L. Boy, Collectif. Pour un Droit Commun de L'Environnement - Mélanges en L'Honneur de Michel Prieur (pp. 577-587). Paris: Dalloz.

Lima, F. D. S., \& Sá, A. J. (2014). 0 materialismo histórico e dialético como método para o entendimento do medo e da violência nos espaços livres públicos urbanos. In Anais do Simpósio Cidades Médias e Pequenas da Bahia (pp. 1-11). Ilhéus: UESB.

Mance, E. A. (2007). O Papel Estratégico do Movimento Popular para a Democracia Popular- o aprendizado dos anos 80 e 90. Brasília: MNDH. Recuperado em 23 de março de 2016, de http://www.solidarius.com.br/mance/ biblioteca/movpop.pdf

Marguti, B. O., Costa, M. A., \& Galindo, E. P. (2016). A trajetória brasileira em busca do direito à cidade: os quinze anos de Estatuto da Cidade e as novas perspectivas à luz da nova agenda urbana. In M. A. Costa. $O$ Estatuto da Cidade e a Habitat III: um balanço de quinze anos da política urbana no Brasil e a Nova Agenda Urbana (pp. 10-25). Brasília: IPEA.

Maricato, E. (2006). O Ministério das Cidades e a política nacional de desenvolvimento urbano (Vol. 12). Brasília: IPEA.

Maricato, E. (2013). Brasil, cidades: alternativas para a crise urbana (7a ed., 204 p.). Petrópolis, RJ: Vozes. 
Mota, J. C. (2007). Uma análise da criação e da atuação do SERFHAU. In Anais do XII Encontro Nacional da ANPUR (pp. 3324-3344). Belém: ANPUR.

Muniz, M. Á. (2006). O Plano Diretor como Instrumento de Gestão da Cidade: o Caso da Cidade de Fortaleza/CE (Dissertação de mestrado). Faculdade de Arquitetura, Universidade Federal do Rio Grande do Norte, Natal.

Oliveira, C. L., Araújo, M. E., Jr. (2007). Democracia participativa e plano diretor dos municípios: alguns problemas teóricos e práticos. In Anais do XV Congresso Nacional do CONPEDI (pp. 6631-6648). Florianópolis: Boiatex.

Oliveira, C. M., Lopes, D. M. J., Colenci, P. L., \& Sousa, I. C. N. (2016). Democracia participativa no direito urbanístico (1a ed., Vol. 1). São Carlos: EdUFSCar.

Oliveira, F. P. (2011). A Discricionariedade de Planeamento Urbanístico Municipal na Dogmática Geral da Discricionariedade Administrativa. Coimbra: Almedina.

Oliveira, J. T., Fo., \& Vasconcellos, C. P. (2011). Democracia e participação popular: as possibilidades de transformações nas formas de gestão do território a partir do Estatuto da Cidade. In Anais do I Circuito de Debates Acadêmicos (11 p.). Brasília: IPEA.

Oliveira, N. B., \& Moreira, F. B. S. (2006). Da elaboração participativa à gestão democrática: considerações sobre a implementação do Plano Diretor Municipal. Recuperado em 30 agosto de 2016, de http://www.laboratoriourbano. ufba.br/wp-content/uploads/arquivos/arquivo-68.pdf

Rodríguez de Santiago, J. M. (2000). La ponderación de bienes e intereses en el Derecho Administrativo. Madrid: Marcial Pons.

Santos, B. S., \& Avritzer, L. (2005). Para ampliar o cânone democrático. In B. S. Santos (Org.), Democratizar a democracia: os caminhos da democracia participativa (3a ed., pp. 39-82). Rio de Janeiro: Civilização Brasileira.

Santos, O. A., Jr., \& Montandon, D. T. (Org.). (2011). Os Planos Diretores Municipais Pós-Estatuto da Cidade: balanço crítico e perspectivas. Rio de Janeiro: Letra Capital, Observatório das Cidades, IPPUR/UFRJ.

Saule, N., Jr., \& Uzzo, K. (2009). The History of Urban Reform in Brazil. DPH - diálogos, propuestas, historias para uma cidadania mundial. Recuperado em 18 de julho de 2016, de http://base.d-p-h.info/pt/fiches/dph/fiche-dph-8535.html

Schneider, L. C., \& Campos, H. Á. (2015). Institucionalidades do planejamento e gestão territorial: desafios da governança democrática numa perspectiva interescalar. In: Anais do XVI ENANPUR - Sessões Temáticas. ST2: Estado, planejamento e política. Belo Horizonte: ANPUR.

Schvarsberg, B. (2013a). Módulo I: Introdução ao Planejamento Urbano. In B. Schvarsberg. Curso Instrumentos do Estatuto da Cidade: Parte 1 - Planejamento Urbano e Plano Diretor (Capacidades - Programa Nacional de Capacitação das Cidades, 32 p.). Brasília: Programa Nacional de Capacitação das Cidades.

Schvarsberg, B. (2013b). Módulo II: Plano Diretor. In B. Schvarsberg. Curso Instrumentos do Estatuto da Cidade: Parte 1 - Planejamento Urbano e Plano Diretor (Capacidades - Programa Nacional de Capacitação das Cidades, 35 p.). Brasília: Programa Nacional de Capacitação das Cidades.

Souza, C. H. L., Cruxên, I. A., Alencar, J. L. O., Lima, P. P. F., \& Ribeiro, U. C. (2013). Ampliação da participação na gestão pública: um estudo sobre conferências nacionais realizadas entre 2003 e 2011. Brasília: Ipea. (Relatório de Pesquisa).

United Nations Human Settlements Programme - UN-HABITAT. (2014). The Evolution of National Urban Policies - A Global Overview (96 p.). Nairóbi: Cities Alliance, Cities Without Slums, United Nations Human Settlements Programme.

Valente, M. A. L. (2006). Democracia enclausurada: um debate crítico sobre a democracia representativa contemporânea (Coleção Parlamento em Teses, n. 2). Brasília: Câmara dos Deputados, Coordenação de Publicações.

Villaça, F. (1999). Uma contribuição para a história do planejamento urbano no Brasil. In C. Deák, S. R. Schiffer (Orgs.), O processo de urbanização no Brasil (pp. 169-243). São Paulo: Fupam/Edusp.

Vizioli, S. H. T. (1998). Planejamento urbano no Brasil: a experiência do SERFHAU enquanto órgão federal de planejamento integrado ao desenvolvimento municipal (Dissertação de mestrado). Faculdade de Arquitetura e Urbanismo, Universidade de São Paulo, São Paulo.

Recebido: Nov. 16, 2016

Aprovado: Jul. 26, 2017 